\title{
Control Method of Impedance Network in SiC Power Converters for HEV/EV.
}

\author{
E. Fernández, A. Paredes V. Sala, L. Romeral \\ Department of Electronics Engineering \\ Technical University of Catalonia. MCIA \\ Campus of Terrassa - Barcelona, 08222 Terrassa (Spain) \\ Phone: +0034 652028756, e-mail: efren.fernandez@mcia.upc.edu
}

\begin{abstract}
Silicon carbide (SiC) devices provide significant performance improvements in many aspects, including lower power dissipation, higher operating temperatures, and faster switching, compared to conventional Si devices. All these features helped increase the interest in the applications of these devices for electric drive systems. The inclusion of an impedance network to elevate DC voltage would improve performance of an electric-traction system, because the topologies of impedances networks can eliminate the need of a DC-DC converter. However, it is important to know control methods that applicable to this type of topologies to systems that are more efficient. This paper presents the analysis of a control method in a power converter topology using $\mathrm{SiC}$ devices with an impedance network to elevate DC voltage for electric traction applications. The proposed analisys includes the implementation of a control method in Current Fed Quasi-Z topology, with 100 $\mathrm{kHz}$ switching frequency, and its analysis using the simulation of the control method, the power losses in $\mathrm{SiC}$ devices and the stress on passive components in the impedance network. Finally, the obtained results are compared with a conventional Current Fed Quasi-Z topology built with silicon devices at a low switching frequency $(2 \mathrm{KHz})$.
\end{abstract}

\section{Key words}

Silicon carbide. , Electric Cars, DC-AC converter.

\section{Introduction}

The application of impedance networks topologies of power converters, used for the development of drive systems for electric vehicles voltage source inverter (VSI) and current source inverter (CSI), has helped overcome the voltage and current limitations that frequently occur in these topologies [1].

In the development of power converters with an input source voltage and impedance network coupling, the voltage can be increased by controlling shooting time intervals through the converter so there is no need for a DC / DC converter [2]. The common schematic of a network with an impedance converter using power semiconductor devices used in drive systems is shown in Fig.1.

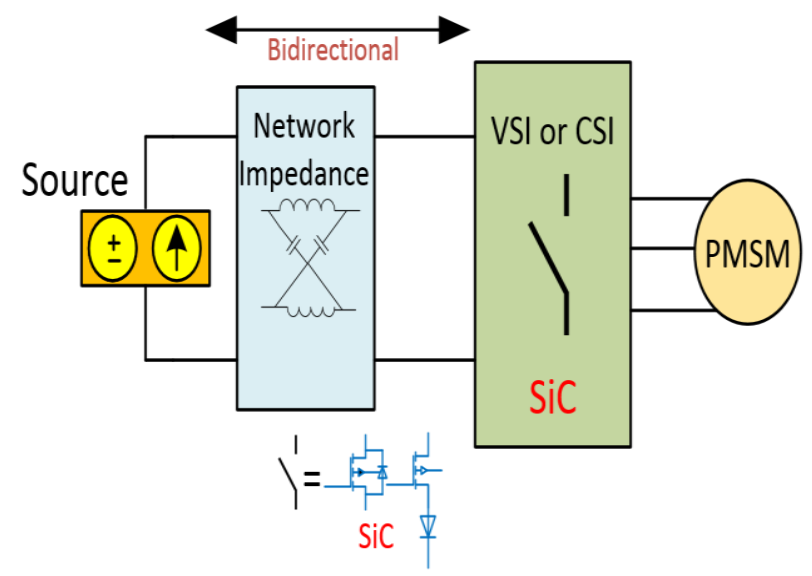

Fig 1. Schematic of power converters $\mathrm{SiC}$ with network impedance for applications in traction system.

A basic network impedance is composed of linear energy storage elements, capacitors and inductors. There is also the possibility of implementing various configurations with the help of semiconductor elements such as switches and diodes [2]. For bidirectional impedance network topologies is necessary to know the different control strategies and modulations types for obtaining the phases, frequencies, voltage amplitude and current in the converter. A new zero switching state called Shootthrough exists in these converts. This state is caused by the short-circuiting of one, two or all three legs of the inverter [3].

This paper contributes the research of power converter topologies that improve the performance of electric traction systems using $\mathrm{SiC}$ elements, and to the research of more efficient control techniques to consolidate these topologies in look for more efficient control techniques to consolidate these topologies in HEV / EV systems.

In this paper, a control method for $\mathrm{SiC}$ power converters with an impedance network is developed. The paper is organized as follows: Section II presents the control methods for impedance networks. Section III presents the design and implementation of a power converter using simulation. Section IV shows the results and comparative analysis with Si topology. Section V summarizes the most important conclusions of the paper. 


\section{Control Methods for Impedance Network}

A network impedance $Z$ has a non-minimum phase behavior, which could be a problem or limitation at the time of designing a control network, for it is very important to obtain a good dynamic model of the converter [4].

The analysis of a small signal model in these topologies can work with different state variables, input current, currents in inductances and voltages in capacitors. The models obtained in this manner provide a transfer function that can be used for controller design, but that also provides features and dynamic system behavior [4] [8].

A diagram or equivalent circuit for small signal analysis in the converter impedance network Quasi $\mathrm{Z}$ is shown in Fig.2, where it is established that SD is the control variables and input voltages or capacitor the which variables to control.

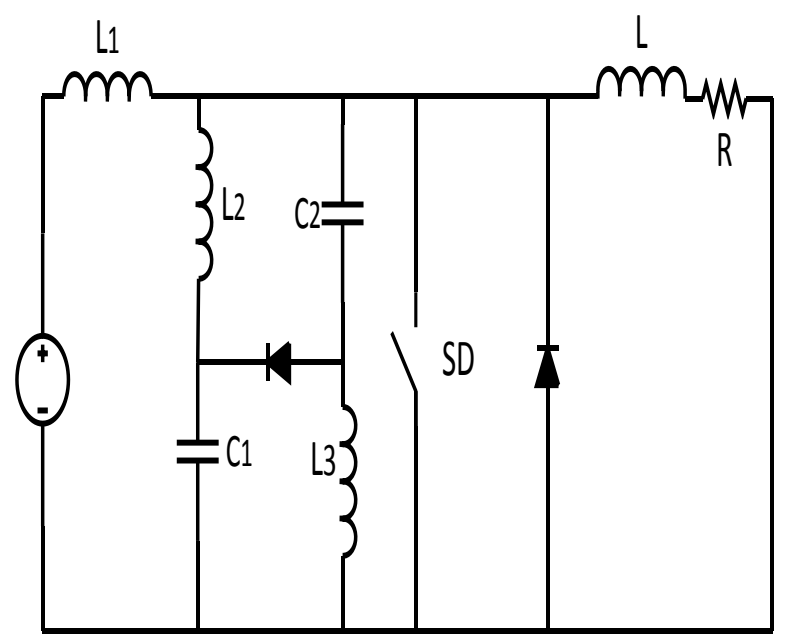

Fig 2. CF-Quasi Z equivalent circuit for small signal analysis.

During the small signal analysis of different topologies, it is important to take into account that bidirectional impedance networks can be symmetrical networks, which means that values of capacitance and inductance are equal $(\mathrm{C} 1=\mathrm{C} 2$ and $\mathrm{L} 1=\mathrm{L} 2)$ [9]-[11]. The voltage or current that enters the inverter can be controlled by two methods: voltage or current control, which can be direct or indirect.

The direct method, show in Fig.3a, improves transient response and minimizes the perturbation. It also facilitates the network impedance controller design. The indirect method, shown in Fig.3b, work with the capacitor voltage or current output inductor, which are measured in order to compare them to a voltage or current reference.

It is very important to take into consideration that when working with the method of indirect control the voltage peak can generate problems, it can become uncontrollable and this could affect the output voltage, causing greater stress to the semiconductors in the inverter and increasing distortion. One way to solve this problem is by modifying the modulation index [12].

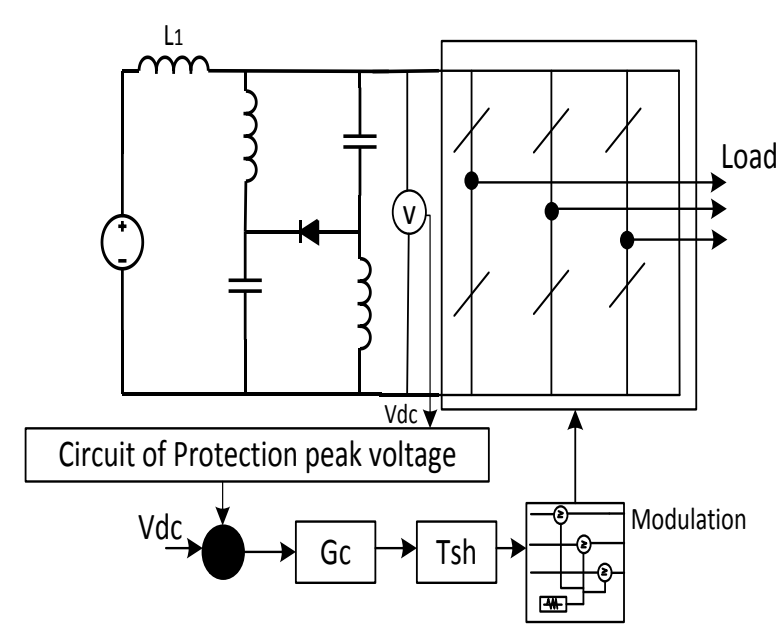

a) Direct control method capacitor voltage Vc.

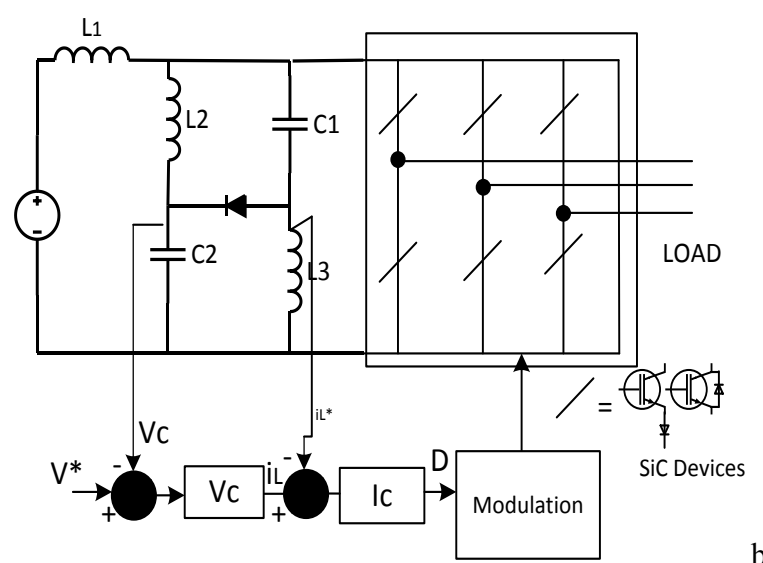

Indirect control voltage capacitor $\mathrm{Vc}$ and IL.

b)

Fig 3. Methods of control direct and indirect for impedance networks.

\section{SiC power converter and Method of Control}

The topology used for this application is the Current Fed Quasi-Z power inverter shown in Figure 3. The Quasi Z topology has two modes of operation; continuous operation and a discontinuous operation.

Only the continuous mode is analyzed in this mode it has three states of operation, in the first state the inverter bridge is an active state and the DC link voltage Vout is equal to the output voltage VDC, and the diode is not active [13], this state is called active state (Fig.4a).

In the second state (Fig. 4b) the inverter bridge is equivalent to a short circuit by turning on the upper and lower switches in the same phase leg, or in the same twophase legs or three phase legs together, the DC link voltage is zero and the diode is off [13]. In the third mode (Fig. 4c), called open state the devices are disconnected, which is similar to an open state, where the diode is turned on and the voltage of DC link is equal to the sum of voltages in each capacitor [13].

Considering that the average voltage over one switching period should be zero in steady state, Vout is calculated using the next expression: 


$$
V_{\text {out }}=\frac{D_{A}+D_{s h}+D_{o p}}{D_{A}}=\frac{1-2 D_{o p}}{D_{A}}
$$

Similarly, considering that; the average current of the capacitors over one switching period should be zero in steady sate. $\mathrm{I}_{\mathrm{L} 1}$ can be calculated as follows:

$$
\begin{aligned}
& I_{L 1}=I_{L 2=} \frac{D_{o p}}{D_{A}+D_{s h}+D_{o p}} I_{i n} \\
& I_{L 1}=I_{L 2=} \frac{D_{o p}}{1-D_{o p}} I_{i n}
\end{aligned}
$$

Where the $D_{A}, D_{\text {sh }}$ and $D_{\text {op }}$ are the duty cycles of the active states, shoot-through state and traditional zero state.

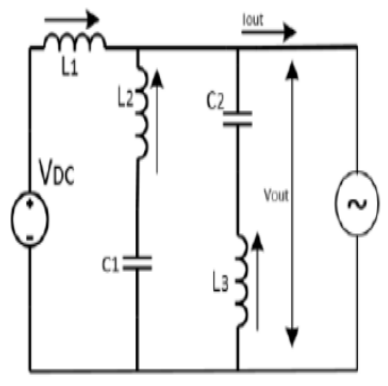

a) State active

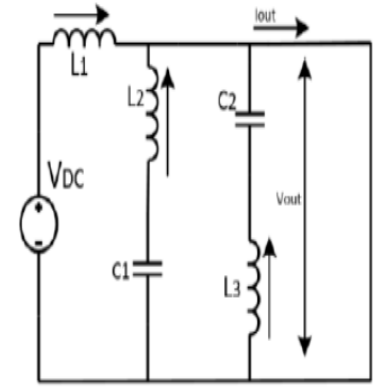

b) Short zero state

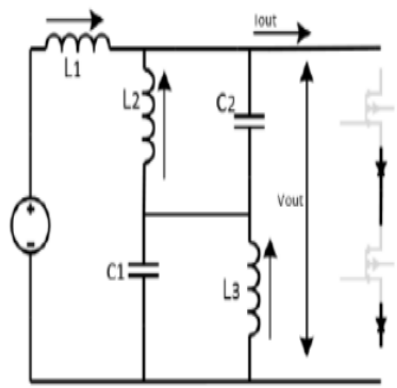

\section{c) Open zero state}

Fig.4. Modes operations in continues.

The differential equations that describe the system shown in Fig. 2 when $\mathrm{SD}$ is on and considering that $\mathrm{L} 1=\mathrm{L} 2=\mathrm{L} 3$ and $\mathrm{C} 1$ $=\mathrm{C} 2$ can be written as:

$$
\begin{aligned}
& \frac{L d i_{L}(t)}{d t}=\left(1-2 D_{O P}\right) V_{c}(t)-V_{o u t}(t)\left(1-2 D_{o p}\right) \\
& \frac{C d i_{C}(t)}{d t}=\left(2 D_{O P}-1\right) I_{L}(t)-D_{o p} I_{D C} \\
& \frac{L_{i} d i_{D C}(t)}{d t}=\left(-2 D_{O P}\right) V_{c}(t)-r I_{D C}(t)+\left(V_{\text {in }}(t)-\right. \\
& \left.\left(1-D_{o p}\right) V_{\text {out }}\right)
\end{aligned}
$$

The system can be represented in matrix form as follows: $\frac{d}{d t}\left[\begin{array}{c}i_{L} \\ V_{C} \\ I_{D C}\end{array}\right]=\left[\begin{array}{ccc}0 & \frac{1-2 D_{o p}}{L} & 0 \\ \frac{2 D o p-1}{C} & 0 & \frac{D o p}{C} \\ 0 & -\frac{2 D o p}{L_{l}} & -\frac{r}{L_{l}}\end{array}\right]\left[\begin{array}{c}i_{L}(t) \\ V_{C}(t) \\ I_{D C}(t)\end{array}\right]+$

$\left[\begin{array}{c}\frac{V_{o u t}}{L}\left(1-D_{o p}\right) \\ 0 \\ V_{\text {in }}-\left(1-D_{\text {Dop }}\right) V_{\text {out }} \\ L\end{array}\right]$

The parameters of the impedance network and data used to obtain the transfer functions of $\mathrm{I}_{\mathrm{L}}$ and $\mathrm{V}_{\mathrm{c}}$ are shown in Table 1.

Table.1 Parameter of Impedance Network

\begin{tabular}{|l|l|}
\hline Parameter & Value \\
\hline Dop & 0,25 \\
\hline $\mathrm{L}=\mathrm{L} 1=\mathrm{L} 2$ & $50 \mathrm{uH}$ \\
\hline Lload & $0.47 \mathrm{mH}$ \\
\hline $\mathrm{C}=\mathrm{C} 1=\mathrm{C} 2$ & $660 \mathrm{uF}$ \\
\hline Vin & $100 \mathrm{~V}$ \\
\hline Rload & $5 \Omega$ \\
\hline
\end{tabular}

Once the system is solved we obtain the following transfer functions:

$$
\begin{aligned}
& G V_{C}(s)=\frac{1.328 e^{-6} s^{2}-0.0794504 s-99.96}{3 e^{-11} s^{3}+5 e^{-8} s^{2}+48000 s+18} \\
& G I_{L}(s)=\frac{9.996 e^{-6} s^{2}-6000.42 s-39.98}{3 e^{-11} s^{3}+5 e^{-8} s^{2}+48000 s+18}
\end{aligned}
$$

With the obtained transfer function, the loop is closed by designing and implementing a PI. A diagram of the closed loop of the converter is presented in Fig 5 [14]

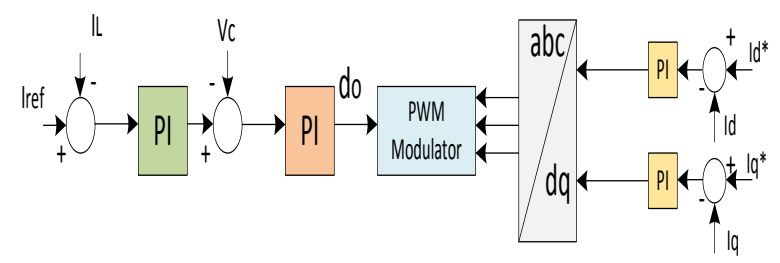

Fig.5. Close loop control of power converter.

The $\mathrm{Id}^{*}$ and $\mathrm{Iq}^{*}$ are the currents of the converter after passing through a transformation. The PI control for these currents is designed to improve the response of the closed loop.

For the tuning of the PI controller for the impedance network, the SiSoTools of Matlab was used, which allows faster and effective tuning when compared with the analytical methods. Moreover it can works directly with the transfer functions. 


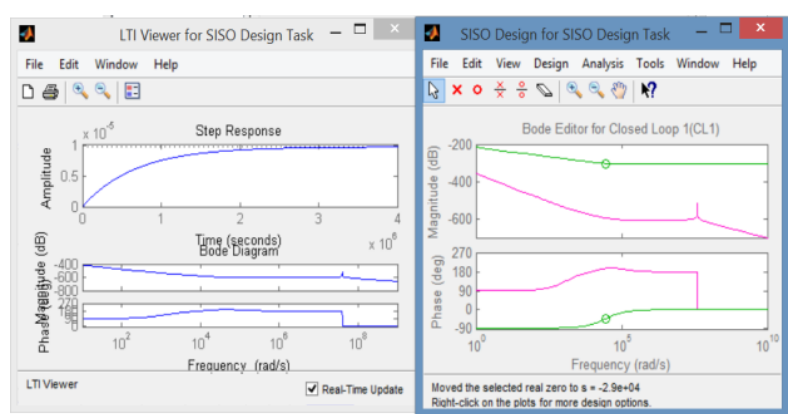

Fig.6. SiSotools tuning of PI controllers.

\section{Simulations and Results}

This section describes the different results obtained in simulation made in Psim. The first part presents the results of the proposed control in the Current Fed Quasi-Z topology (Fig.7). Next, a comparative study between the topology with the proposed control and a topology with silicon devices is performed. Power losses and stress analyzes on passive devices are also performed.

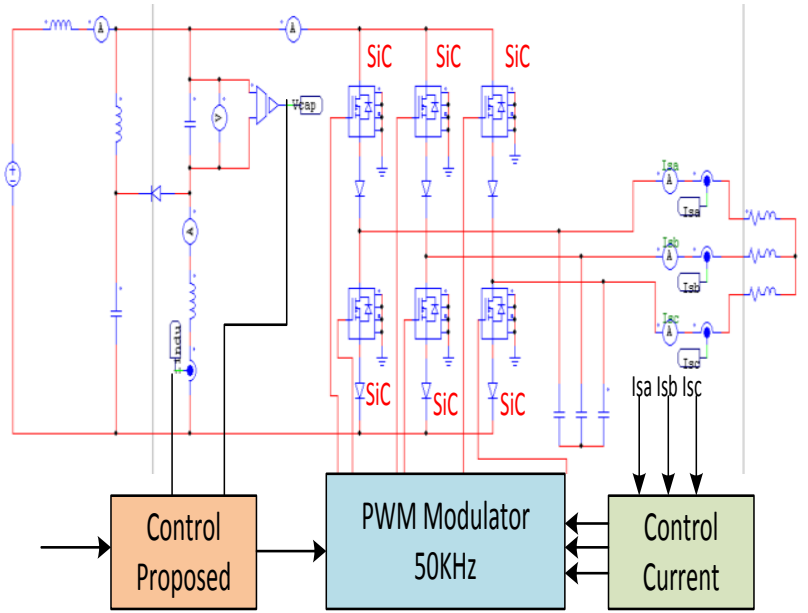

Fig.7. Topology Current Fed Quasi-Z and control proposed.

The Simulation parameters are shown in Table 2:

Table.1 Parameter of simulations

\begin{tabular}{|l|l|}
\hline Parameter & Value \\
\hline Vdc & $100 \mathrm{~V}$ \\
\hline $\mathrm{L}=\mathrm{L} 1=\mathrm{L} 2$ & $50 \mathrm{uH}$ \\
\hline $\mathrm{C}=\mathrm{C} 1=\mathrm{C} 2$ & $660 \mathrm{uF}$ \\
\hline Frequency & $50 \mathrm{KHz}$ \\
\hline C Filter & $10 \mathrm{uF}$ \\
\hline Mosfet SiC & SCT2450KE \\
\hline Diode $\mathrm{SiC}$ & $\mathrm{C} 3 \mathrm{D} 08065 \mathrm{I}$ \\
\hline Pi of current & $\begin{array}{l}\mathrm{P}=0.6 \\
\mathrm{I}=0.053\end{array}$ \\
\hline Pi of voltage & $\begin{array}{l}\mathrm{P}=0.8 \\
\mathrm{I}=0.0034\end{array}$ \\
\hline Pi of Id and $\mathrm{Iq}$ & $\mathrm{P}=2.2 ; \mathrm{I}=0,23$ \\
\hline
\end{tabular}

In the Fig. 8, the control results of the impedance network are shown.

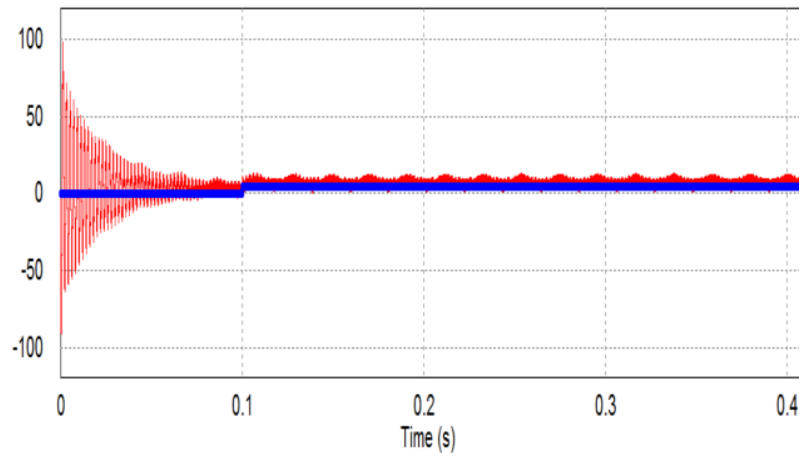

a) Current control in the impedance network.

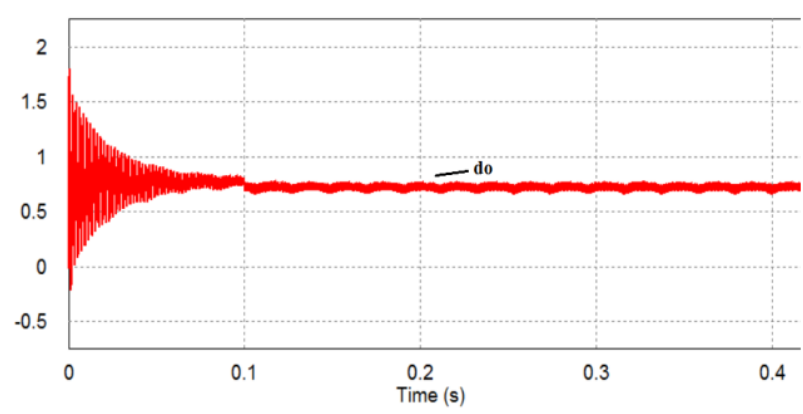

b) Voltage control in impedance network.

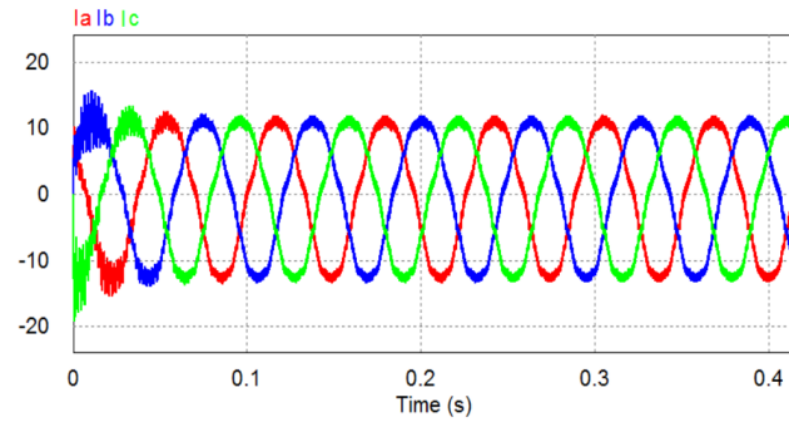

c) Currents Ia, Ib, Ic in the power converter.

Fig.8. Current and do control in the impedance network.

The Fig.9, shows the stress on the elements of the impedance network.

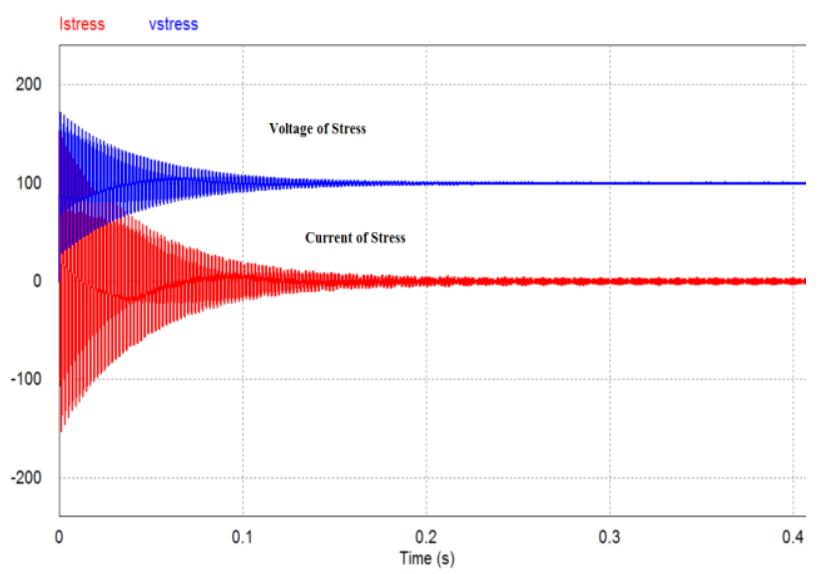

Fig. 9. Stress in passive elements.

The Pi control of Id and Iq are shown in Fig.10 


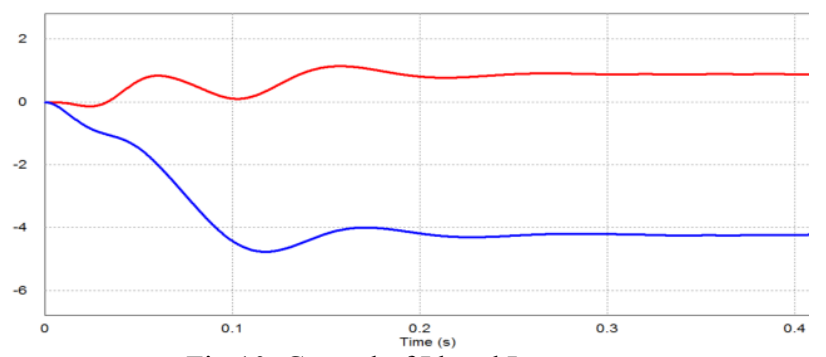

Fig.10. Control of Id and Iq currents.

When the PI control in the impedance network is not properly tuned, the currents are distorted and can cause problems in the system (Fig.10).

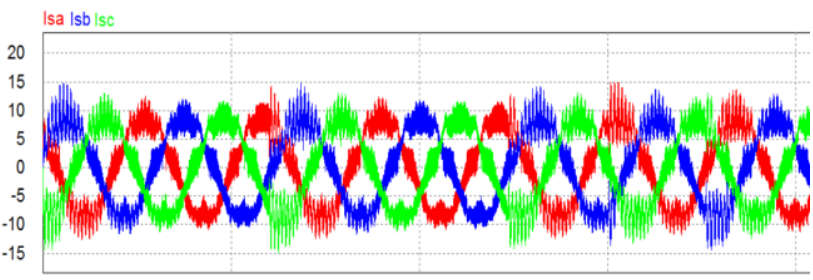

a) Currents with badly tuned in Pi control of current and voltage in impedance network.

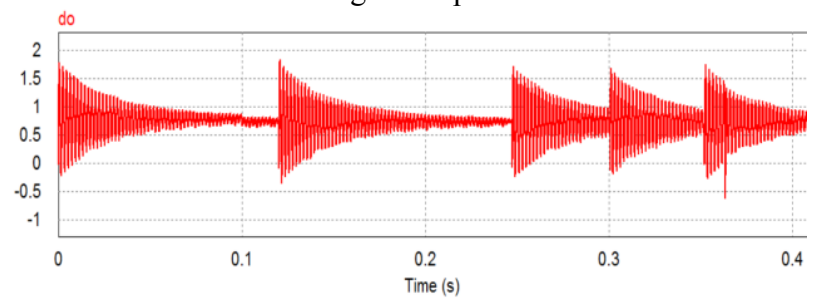

b) Impedance Network do with bad tuning. Fig.10. Results of control badly tuned.

The analisys of power losses by conduction and switching in the porposed topology are presented in Fig.11.

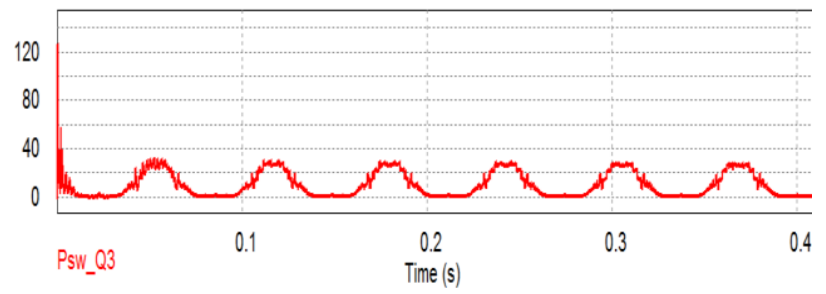

a) Conduction power losses in $\mathrm{SiC}$ Mosfet.

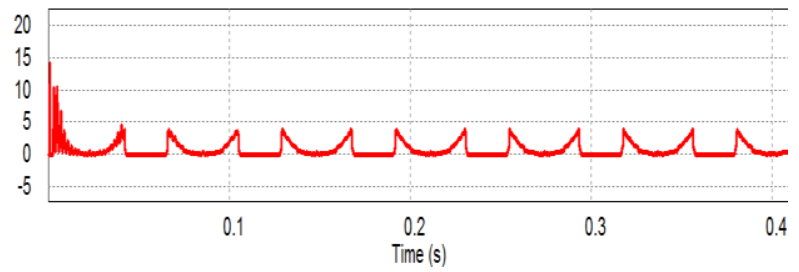

b) Switching power losses in SiC Mosfet.

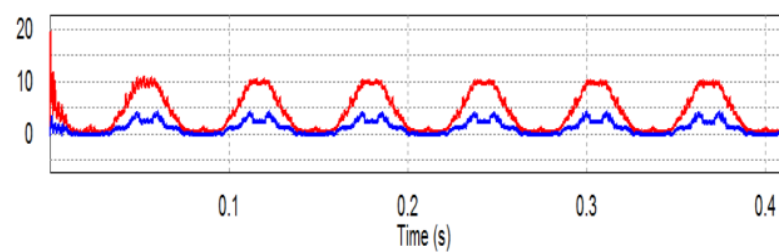

c) Conduction and switching power losses in $\mathrm{SiC}$ Diode Fig.11. Analisys of power losses in Current Fed Quasi-Z SiC topology.
The results of the power losses analysis in Current Fed Quasi-Z Si topology are presents in the Fig.12; the switching frequency is $10 \mathrm{KHz}$.

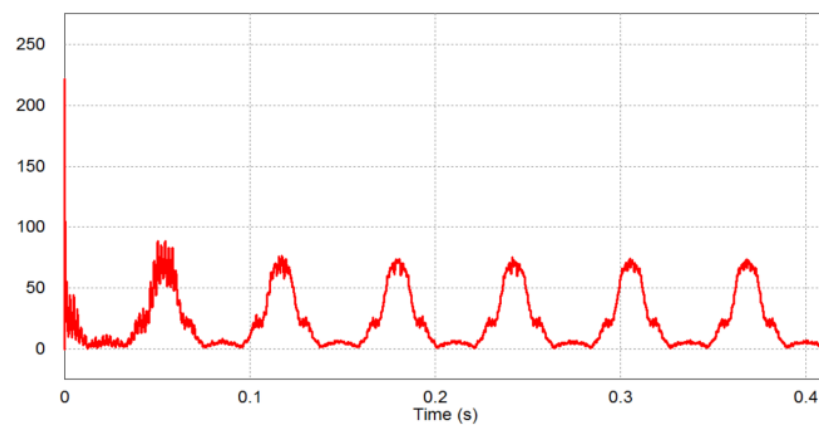

a) Conduction power losses in Si IGBTs.

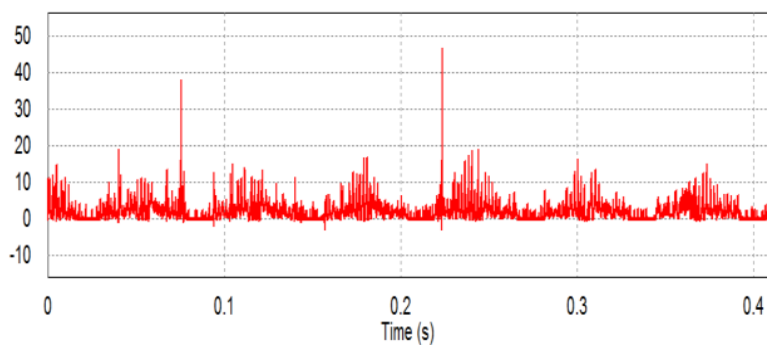

b) Switching power losses in Si IGBTs.

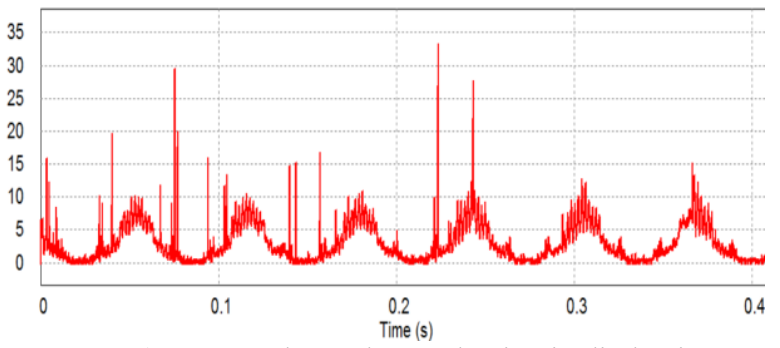

c) Power losses by conduction in diode $\mathrm{Si}$

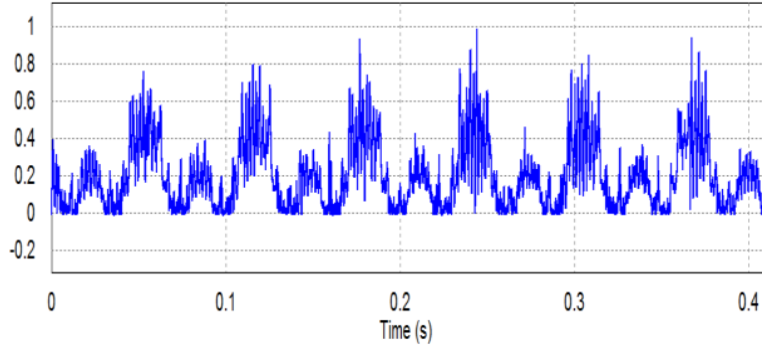

d) Power losses by switching in the Si diode.

Fig.11. Analisys of power losses in Current Fed Quasi-Z Si topology.

Analyzing the results of the power losses between the two topologies it can be established that the proposed topology has less power losses when $\mathrm{SiC}$ devices are used.

\section{Conclusions}

This paper presents a control method for Current Fed Quasi-Z SiC topology. The proposed method allows to control the impedance network; and to generate the PWM signals for the $\mathrm{SiC}$ devices in the converter.

The implemented method was found acceptable during the simulation. Therefore, the obtained results support the development of the application, showing improved performance over the other studied topologies. 
In the comparative study between the two topologies $\mathrm{SiC}$ and $\mathrm{Si}$, the results show that the power losses in the proposed topology are reduced. The reason is that the uses $\mathrm{SiC}$ devices, which allow a higher activation frequency.

This research showed the advantages of $\mathrm{SiC}$ based topologies with different control techniques. The proposed control helped to improve the design of the impedance network and to reduce the stress and size of the passive components within the network.

Power converters that use an impedance network are emerging topologies for drive systems in HEV / EV. The use of SiC devices in these topologies and the application of control methods that focus on improving the efficiency can contribute to the consolidation of these technologies within these systems.

\section{ACKNOWLEDGMENT.}

This work was supported in part by the Spanish Ministry of Economy and Competitiveness under the TRA201680472-R Research Project.

\section{REFERENCES}

[1] Siwakoti, Y.P.; Fang Zheng Peng; Blaabjerg, F.; Poh Chiang Loh; Town, G.E., "Impedance-Source Networks for Electric Power Conversion Part I: A Topological Review," in Power Electronics, IEEE Transactions on, vol.30, no.2, pp.699-716, Feb. 2015 doi: 10.1109/TPEL.2014.

[2] Yamashita, N.; Asano, M.; Yamanaka, M.; Koizumi, H., "A $\mathrm{Z}$-source inverter accepting rapid reverse current flow," in TENCON 2010 - 2010 IEEE Region 10 Conference, vol., no., pp.48-53, 21-24 Nov. 2010 TENCON.2010.

[3] F. Z. Peng, "Z-source inverter," IEEE Trans. Ind. Appl., vol. 39, pp.504-510, Mar/Apr 2003.

[4] Y. P. Siwakoti, F. Z. Peng, F. Blaabjerg, P. C. Loh, G. E. Town and S. Yang, "Impedance-Source Networks for Electric Power Conversion Part II: Review of Control and Modulation Techniques," in IEEE Transactions on Power Electronics, vol. 30, no. 4, pp. 1887-1906, April 2015.

[5] A. Battiston, E. H. Miliani, J. P. Martin, B. NahidMobarakeh, S.Pierfederici and F. Meibody-Tabar, "A Control Strategy for Electric Traction Systems Using a PMMotor Fed by a Bidirectional Z-Source Inverter," in IEEE Transactions on Vehicular Technology, vol. 63, no. 9, pp. 4178-4191, Nov. 2014.

[6] M. Ismeil, M. Orabi, R. Kennel, O. Ellabban and H. AbuRub, "Experimental studies on a three phase improved switched Z-source inverter," 2014 IEEE Applied Power Electronics Conference and Exposition -APEC 2014, Fort Worth, TX, 2014, pp. 1248-1254.

[7] O. Ellabban, J. Van Mierlo and P. Lataire, "A DSP-Based Dual-Loop Peak DC-link Voltage Control Strategy of the Z-Source Inverter," in IEEE Transactions on Power Electronics, vol. 27, no. 9, pp. 4088-4097, Sept. 2012

[8] Y. Liu, H. Abu-Rub and B. Ge, "Z-Source/Quasi-Z-Source Inverters: Derived Networks, Modulations, Controls, and Emerging Applications to Photovoltaic Conversion," in IEEE Industrial Electronics Magazine, vol. 8, no. 4, pp. 3244, Dec. 2014.

[9] A. Battiston, J. P. Martin, E. H. Miliani, B. NahidMobarakeh, S. Pierfederici and F. Meibody-Tabar, "Comparison Criteria for Electric Traction System Using ZSource/Quasi Z-Source Inverter and Conventional
Architectures," in IEEE Journal of Emerging and Selected Topics in Power Electronics, vol. 2, no. 3, pp. 467-476, Sept. 2014.

[10] J. Anderson and F. Z. Peng, "Four quasi-Z-Source inverters," 2008 IEEE Power Electronics Specialists Conference, Rhodes, 2008, pp. 2743-2749.

[11] Y. Li and F. Z. Peng, "AC small signal modeling, analysis and control of quasi-Z-Source Converter," Power Electronics and Motion Control Conference (IPEMC), 2012 7th International, Harbin, China, 2012, pp. 1848-1854.

[12] G. Sen and M. E. Elbuluk, "Voltage and CurrentProgrammed Modes in Control of the Z-Source Converter," in IEEE Transactions on Industry Applications, vol. 46, no. 2, pp. 680-686, March-April 2010.

[13] Q. Lei, F. Z. Peng and S. Yang, "Discontinuous operation modes of current-fed Quasi-Z-Source inverter," Applied Power Electronics Conference and Exposition (APEC), 2011 Twenty-Sixth Annual IEEE, Fort Worth, TX, 2011, pp. 437-441.

[14] Yushan Liu, Haitham Abu-Rub, Baoming Ge, Frede Blaabjerg, Omar Ellabban, Poh Chiang Loh Impedance Source Power Electronic Converters ISBN: 978-1-11903707-1, Book October 2016, Wiley-IEEE Press. 